\title{
KENDALI LAMPU OTOMATIS MENGGUNAKAN SENSOR LIGHT DEPENDENT RESISTOR (LDR) BERBASIS MIKROKONTROLLER ARDUINO
}

\author{
${ }^{1}$ Nuris Subakhil Laili Eka Prasetya \\ ${ }^{1}$ Jurusan Teknik Informatika, Fakultas Teknik Universitas Yudharta Pasuruan \\ 1e-mail : Nuris.shobail@gmail.com
}

\begin{abstract}
ABSTRAK
Semakin berkembangnya jaman, saat ini otomatisasi cukup banyak digunakan untuk berbagai keperluan guna memudahkan pekerjaan manusia, dari hal yang vital sampe hal yang sepele, Sistem kendali dalam hal ini sebagai bidang ilmu yang memungkinkan implementasi otomatisasi. Pada penelitian ini, sistem kendali diterapkan untuk mengendalikan lampu secara otomatis menggunakan sensor cahaya. Pengendali yang digunakan adalah mikrokontroler Arduino - Mikrokontroler berfungsi untuk memproses sinyal masukkan dari sensor cahaya sebagai komponen umpan balik, kemudian menghasilkan keluaran yang ditujukan pada aktuator dalam hal ini adalah relay. Program yang diterapkan pada mikrokontroler berfungsi untuk melakukan inisialisasi dan konfigurasi perangkat keras serta membaca sinyal masukkan dari sensor cahaya yang kemudian memprosesnya dengan diberikan beberapa kondisi sampai menghasilkan keluaran. Hasil akhir penelitian ini adalah sistem penerangan otomatis untuk mengendalikan lampu berdasarkan pengukuran intensitas cahaya oleh sensor disekitar lampu yang kemudian dikonversi menjadi nilai ADC. Lampu akan menyala secara otomatis jika nilai ADC 0-60 dan sebaliknya lampu akan mati secara otomatis jika nilai ADC 61-102.
\end{abstract}

Kata Kunci: sistem penerangan otomatis, mikrokontroler

\section{PENDAHULUAN}

Sistem kendali secara otomatis di bidang ilmu pengetahuan dan teknologi belakangan ini berkembangan dengan pesat. Dengan adanya kemajuan di bidang ilmu pengetahuan dan teknologi menghasilkan inovasi baru yang berkembang menuju lebih baik. Hal ini dapat dilihat dari jangkauan aplikasinya mulai dari rumah tangga hingga peralatan yang canggih.

Berangkat dari masalah tersebut, maka peneliti ingin membuat sebuah inovasi yang tentunya sangat membantu dalam mengurangi pemborosan energi listrik ini yang apabila dibiarkan saja tanpa ada pencegahan maka pasokan energi listrik akan semakin habis percuma. Peneliti ingin membuat sebuah rancangan prototype lampu rumah otomatis berbasis mikrokontroller Arduino.

\section{LANDASAN TEORI}

\subsection{Arduino}


JURNAL EXPLORE IT!

Vol. 9 No. 1 - Desember 2017

p-ISSN 2086-3489 (Print)- e-ISSN 2549-354X (Online)

Avaiable online at http://jurnal.yudharta.ac.id/v2/index.php/EXPLORE-IT/

Arduino adalah pengendali mikro single-board yang bersifat open-source, diturunkan dari Wiring platform, dirancang untuk memudahkan penggunaan elektronik dalam berbagai bidang. Hardwarenya memiliki prosesor Atmel AVR dan softwarenya memiliki bahasa pemrograman sendiri. pemrograman C. Karena sifatnya yang terbuka maka siapa saja dapat mengunduh skema hardware arduino dan membangunnya.

Harga terjangkau Dapat dijalankan diberbagai sistem operasi, Windows, Linux, Mac, dan

sebagainya.

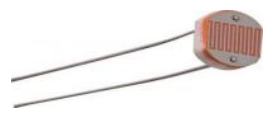

\subsection{Sensor}

Sensor yang sering digunakan dalam berbagai rangkaian elektronik salah satunya adalah sensor cahaya (LDR). Sensor cahaya adalah alat yang digunakan dalam bidang elektronika yang berfungsi untuk mengubah besaran cahaya menjadi besaran listrik. Sensor cahaya LDR (Light Dependent Resistor) merupakan suatu jenis resistor yang peka terhadap cahaya. Nilai resistansi LDR akan berubah-ubah sesuai dengan intensitas cahaya yang diterima. Jika LDR tidak terkena cahaya maka nilai tahanan akan menjadi besar (sekitar $10 \mathrm{M} \Omega$ ) dan jika terkena cahaya nilai tahanan akan menjadi kecil (sekitar 1k $\Omega$ ). (Novianty,Lubis,\& Tony, $2012: 1$ ).

\section{Gambar Sensor LDR}

Dari uraian di atas dapat dinentukan bahwa perlu beberapa port pada mikrokontroler untuk pengontrolan lampu menggunakan sensor cahaya LDR. Satu port dihubungkan ke lampu dan satu port lagi dihubungkan ke sensor LDR. Port ini hanya bisa mendeteksi data digital. Karena lampu yang digunakan ON pada saat diberikan nilai digital “' ', maka Lampu ON maka port tersebut bernilai "1", dan jika Lampu OFF maka port tersebut bernilai “0”.

Jika digambarkan dalam bentuk gelombang, maka akan tampil seperti berikut:

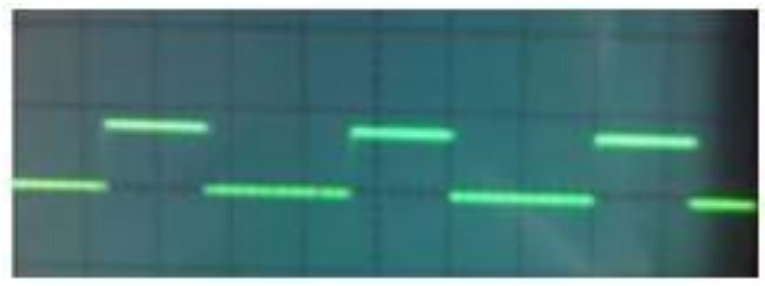

Gambar 3.03. Bentuk Gelombang (a) pada saat lampu OFF 


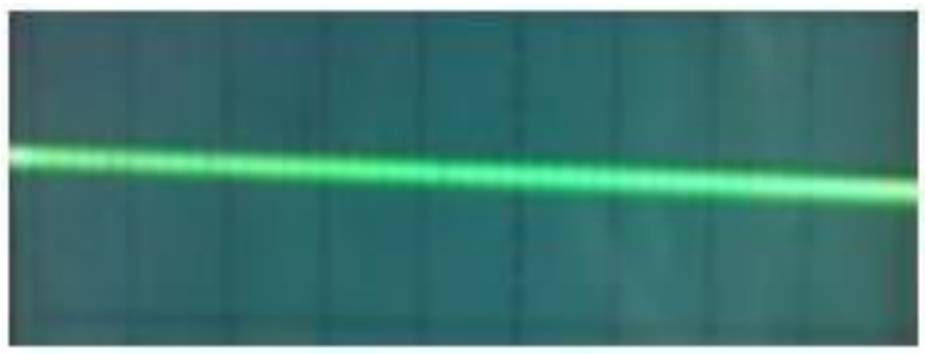

Gambar 3.04. Bentuk Gelombang (a) pada saat lampu ON

Karakteristik LDR terdiri dari dua macam yaitu Laju Recovery dan Respon Spektral:

1. Laju Recovery

Laju recovery merupakan suatu ukuran praktis dan suatu kenaikan nilai resistansi dalam waktu tertentu. Harga ini ditulis dalam K/detik, untuk LDR tipe arus harganya lebih besar dari 200K/ detik(selama 20 menit pertama mulai dari level cahaya 100 lux), kecepatan tersebut akan lebih tinggi pada arah sebaliknya, yaitu pindah dari tempat gelap ke tempat terang yang memerlukan waktu kurang dari $10 \mathrm{~ms}$ untuk mencapai resistansi yang sesuai dengan level cahaya 400 lux.

2. Respon Spektral

LDR tidak mempunyai sensitivitas yang sama untuk setiap panjang gelombang cahaya yang jatuh padanya (yaitu warna). Bahan yang biasa digunakan sebagai penghantar arus listrik yaitu tembaga, aluminium, baja, emas dan perak. Dari kelima bahan tersebut tembaga merupakan penghantar yang paling banyak, digunakan karena mempunyai daya hantaryang baik (TEDC,1998)

\subsection{Catu daya}

Catu daya berfungsi untuk memberikan suplay tegangan, khususnya ke IC mikrokontroler Arduino, catu daya yang di gunakan adalah 5 Volt dc. Untuk menurunkan tegangan trafo dari $9 \mathrm{~V}$ menjadi $5 \mathrm{~V}$ maka di gunakan IC voltage regulator LM7805.Pada rangkaian catu daya, dioda 1N4001 berfungsi sebagai penyearah gelombang penuh dari AC ke DC dengan arus sebesar 2 Ampere, sedangkan kapasitor 100nF berfungsi sebagai filter tegangan DC atau penghalus pulsapulsa tegangan yang dihasilkan oleh dioda penyearah.

Gambar Catu Daya 


\subsection{Softwere Arduino}

Software arduino yang digunakan adalah driver dan IDE, IDE atau Integrated Development Environment merupakan suatu program khusus untuk suatu komputer agar dapat membuat suatu rancangan atau sketsa program untuk papan Arduino. IDE arduino merupakan software yang sangat canggih ditulis dengan menggunakan java.

Gambar 3.07. ToolbarArduino

ditulis dengan menggunakan java. IDE arduino terdiri dari :

Keterangan :

- $\quad$ Editor Program

Sebuah window yang memungkinkan pengguna menulis dan mengedit program dalam bahasa processing.

- Verify

Mengecek kode sketch yang error sebelum mengupload ke board arduino

- Uploader

Sebuah modul yang memuat kode biner dari komputer ke dalam memori di dalam papan arduino.

- New

Membuat sebuah sketch baru.

- Open

Membuka daftar sketch pada sketchbook arduino.

- Save

Menyimpan kode sketch pada sketchbook.

- Serial Monitor

Menampilkan data serial yang dikirimkan dari board arduino. (Sumber : Syahwil,2013:42)

\subsection{Komputer $(\mathrm{PC})$}

Di butuhkan saat akan menulis kode program yang selanjutnya di upload ke board arduino, Arduino adalah software open source yang memudahkan anda untuk menulis kode program dan meng-upload-nya ke board Arduino. Software Arduino dapat berjalan pada Windows, Mac OS X, 
dan Linux. Software ini ditulis dalam bentuk Java dan berbasis processing, avr-gcc, dan perangkat lunak open source lainnya sehingga membutuuhkan komputer (PC) dengan spesifiikasi rendah

\section{METODE PENELITIAN}

\section{Perancangan Perangkat lunak (Software)}

Pada penelitian ini digunakan perangkat lunak Arduino untuk proses pemrograman pada mikrokontroller Arduino.

\subsection{Bahasa Pemrograman}

Fungsi bahasa pemrograman yaitu memerintah komputer untuk mengolah data sesuai dengan alur berpikir yang kita inginkan. Keluaran dari bahasa pemrograman tersebut berupa program/aplikasi.

Bahasa pemrograman komputer yang kita kenal antara lain adalah Java, Visual Basic, C++, C, Cobol, PHP, .Net, dan bahasa lainnya. Namun tentu saja kebutuhan bahasa ini harus disesuaikan dengan fungsi dan perangkat yang menggunakannya. (Sumber:https://id.m.wikipedia.org/wiki/bahasa_pemrograman)

\section{PENGUJIAN DAN HASIL}

\subsection{Pengujian Sensor LDR}

Pada pengujian sensor LDR ini, peneliti menggunakan sebuah Lilin pada kondisi gelap yang diletakkan pada jarak-jarak yang telah ditentukan, pertama untuk jarak $20 \mathrm{~cm}, 40 \mathrm{~cm}, 100 \mathrm{~cm}$ dan juga pada kondisi gelap. Hal ini dilakukan agar dapat mendeteksi hambatan secara tepat kerena adanya intensitas cahaya yang berbeda dan juga berfungsi atau tidak nya alat tersebut. Pengujian sensor LDR dilakukan dengan menjalankan sistem dan menghubungkan output rangkaian sensor LDR dengan multitester digital. Pengujian ini bertujuan untuk mengetahui hambatan terhadap cahaya dan tegangan yang akan dikeluarkan oleh sensor LDR. Pada mulanya LDR diberi cahaya, ini dilakukan agar perubahan keluaran tegangan LDR terhadap perubahan cahaya dapat dideteksi. Adapun hasil pengujian sensor LDR pada input dan output dapat dilihat pada table 
Table01. Pengujian Sensor LDR

\begin{tabular}{|c|c|c|c|c|c|}
\hline \multirow{7}{*}{$\begin{array}{c}\text { Sensor } \\
\text { LDR }\end{array}$} & \multirow{2}{*}{$\begin{array}{c}\text { Jarak } \\
(\mathrm{cm})\end{array}$} & \multicolumn{3}{|c|}{ Pengulangan } & \multirow{2}{*}{ Rata - Rat } \\
\hline & & 1 & 2 & 3 & \\
\hline & 20 & 1.7 & 1.4 & 1.5 & 1.53 \\
\hline & 40 & 2.1 & 2.4 & 2 & 2.17 \\
\hline & 60 & 4.7 & 4.5 & 4.4 & 4.53 \\
\hline & 80 & 5.2 & 5.3 & 5.2 & 5.23 \\
\hline & 100 & 5.1 & 5.2 & 5.3 & 5.20 \\
\hline
\end{tabular}

\subsection{Pengujian Relay}

Pengujian selanjutnya yaitu pengujian relay yang ada pada tiap-tiap ruangan. Tujuan pengujian relay adalah melihat proses pada relay sudah sesuai dengan yang diinginkan. Sistematika proses pada relay masing-masing ruangan sama, yaitu:

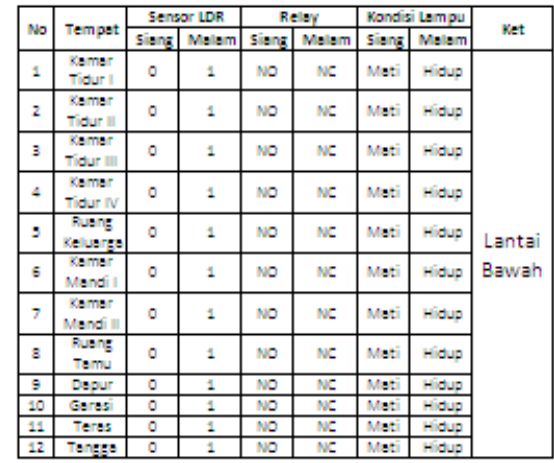

Table 4.02. Lantai Bawah

\begin{tabular}{|c|c|c|c|c|c|c|c|c|}
\hline 8 & kemer Tourl & 0 & 1 & No & NE & Meti & moup & \multirow{6}{*}{$\begin{array}{c}\text { Lantai } \\
\text { Atas }\end{array}$} \\
\hline \begin{tabular}{|l|}
14 \\
\end{tabular} & Kamer Tiour I & 0 & 1 & No & NE & Msti & Rioup & \\
\hline .9 & Kamer Tidur & 0 & 1 & no & ne & Meti & hioup & \\
\hline 16 & kamer Mandi & 0 & 1 & No & NE & Mati & Tioup & \\
\hline 17 & Depur & 0 & 1 & No & NE & Mati & Rioup & \\
\hline & $\begin{array}{l}\text { Rus? } \\
\text { Ke us:at }\end{array}$ & 0 & 1 & no & NE & Meti & risup & \\
\hline
\end{tabular}

\subsection{Pengujian perangkat Lunak (softwere)}

Pengujian pada program mikrokontroler Arduino ini dilakukan dengan menghubungkan input rangkaian sensor LDR dengan rangakaian mikrokontroler Arduino dan menghubungkan output dari rangkaian relay dengan lampu, kemudianmemberikan program. Program-program tersebut dapat bekerja sesuai keadaan yang telah ditentukan dengan cara menghubungkan kaki pin input dan port output. Sedangkan listing programnya dapat dilihat sebagai berikut:

int led $=1$

int cahaya; //variabel nilai besaran cahaya 
$\operatorname{void} \operatorname{setup}()\{$

pinMode(led, OUTPUT);

//Serial.begin(9600); //set serial port utk komunikasi USB

\}

void $\operatorname{loop}()\{$

cahaya $=$ analogRead(A1); //membaca nilai sensor

Serial.println(cahaya); //tampilkan nilai cahaya ke serial USB

if (cahaya $>=60)\{$

digitalWrite(led, LOW); //jika nilai cahaya lebih dr 100 maka buka/nyala

\}

else \{

digitalWrite(led, HIGH); //

\}

delay(500);//jeda 1 detik

\}

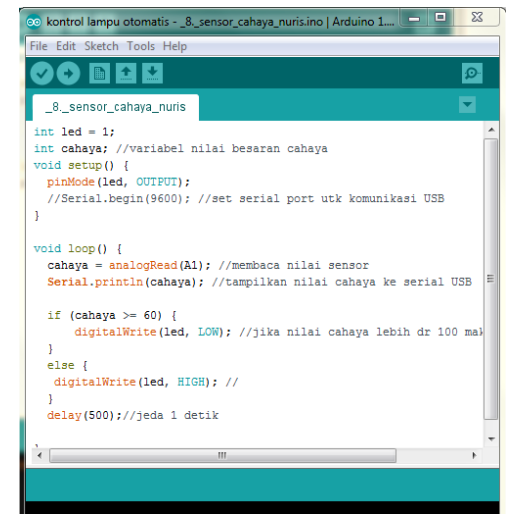

Gambar 4.02. Script arduino

\subsection{Hasil}

LDR merupakan resistor tidak tetap otomat, dibuat dari Cadmium Sulfida yang peka terhadap cahaya. Seperti yang telah diketahui bahwa cahaya memiliki dua sifat yang berbeda yaitu 
sebagai gelombang elektromagnetik dan foton/partikel energi (dualisme cahaya). LDR akan mempunyai hambatan yang sangat besar saat tak ada cahaya yang mengenainya (gelap). Dalam kondisi ini hambatan LDR, mampu mencapai $1 \mathrm{M} \Omega$ (Mega Ohm). Akan tetapi saat terkena sinar, hambatan LDR akan turun secara drastis hingga nilai beberapa puluh ohm saja.

Data di atas menunjukan perbandingan daya lampu yang di gunakan dan daya lampu yang tetap menyala walau tidak di gunakan (lupa tidak di matikan), daya lampu yang di gunakan sebanyak 1220 wh dan daya lampu yang tidak di gunakan sebanyak 930 atau sekitar $74.22 \%$ setiap hari nya.

Lain halnya jika menggunakan prototype penerangan rumah berbasis mikrokontroller Arduino uno, dimana hidup matinya lampu di kendalikan secara otomatis dengan dipengaruhi oleh keadaan cuaca diluar ruangan tersebut, sehingga tidak ada lagi kelalaian yang terjadi dan energi listrik tidak terbuang percuma begitu saja.

\section{KESIMPULAN DAN SARAN}

\subsection{Kesimpulan}

Kesimpulan dari hasil perancangan dan pengamatan pada prototype penerangan rumah berbasis Arduino adalah sebagai berikut:

1 berhasil merancang prototype penerangan rumah berbasis Arduino dengan menggunakan sensor cahaya LDR, dimana sensor cahaya LDR ini memengang peranan penting pada penerangan lampu rumah.

a. dimana setiap ruangan di kontrol untuk dapat secara efisian menghidupkan dan mematikan lampu secara otomatis dengan mengacu pada sensor cahaya LDR untuk menghidupkan dan mematikan lampu secara otomatis

b. tidak perlu bingung dengan lampu rumah saat sedang bepergian atau mudik karena pada saat kurang cahaya (gelap) maka lampu akan hidup sendiri

c. menghemat listrik karena lampu akan mati saat tidak di perlukan

2 Dari hasil survey yang dilakukan dapat diketahui bahwa tingkat kelalaian masyarakat untuk mematikan lampu ketika tidak dipergunakan lagi sangatlah memprihatinkan. Ini terbukti dari alasan mereka lupa mematikan lampu sebesar $70 \%$. 
JURNAL EXPLORE IT!

Vol. 9 No. 1 - Desember 2017

p-ISSN 2086-3489 (Print)- e-ISSN 2549-354X (Online)

Avaiable online at http://jurnal.yudharta.ac.id/v2/index.php/EXPLORE-IT/

\subsection{SARAN}

Sehubungan masih banyaknya kekurangan dan ketidaksempurnaan alat ini, maka penulis menyarankan bagi peneliti selanjutnya beberapa hal yang harus ditambahkan agar alat ini bisa lebih baik, diantaranya:

1. Pada kamar tidur sebaiknya ditambah sensor pendeteksi tidur agar tidak perlu mematikan lampu jikalau ada orang yang tidak suka terang pada saat tidur.

2. Untuk lampu tidur sebaiknya digunakan lampu 220 Volt kerena pada penelitian ini, peeneliti hanya menggunakan lampu LED.

\section{DAFTAR PUSTAKA}

Admayadi. 2010.Otomasi Pengendali Penerangan Ruangan Berbasis Mikrokontroler ATmega8535 Menggunakan Teknologi Fuzzy.Skripsi UIN SUSKA, Pekanbaru.

Azizah Nor Ahmad. 2011.Purwarupa Sistem Otomasi Buka Tutup Tirai Berbasis Light Dependent Resistor.Skripsi UGM Jogjakarta.

IrawanFajar. 2016.Sistem Kendali Lampu Via Wireless 2,4 GHz Berbasis Mikrokontroller ATMega 16.Skripsi Universitas Negri yogyakarta.

Kurniawan Eddi. 2013. Sistem Penerangan Rumah Otomatis Dengan Sensor Cahaya Berbasis Mikrokontroller.Jurnal Coding Sistem Komputer. Vol01 No. 2, 2013.pp. 1 - 10 SupriyantoAnggit. 2013.Rancangan Bangun Kendali Lampu Menggunakan Mikrokontroller ATMega 8538 Berbasis Android Melalui Bluetooth dan Speech Recognition.Skripsi AMIKOMYogyakarta.

Yuliza. 2016. Perancangan lampu Taman Solar Cell Otomatis Untuk Menggunakan Mikrokontroller Arduino Uno.JurnalElektro.Vol.7 No.1 Januari 2016.pp. 37-44. 